\title{
UM MÉTODO PRÁTICO PARA A DEFINIÇÃO DOS AJUSTES DE RELÉS BASEADOS EM MEDIDAS DE FREQÜÊNCIA USADOS PARA DETECÇÃO DE ILHAMENTO DE GERAÇÃO DISTRIBUÍDA
}

\author{
José Carlos M. Vieira* \\ Diogo Salles ${ }^{\dagger}$ \\ Walmir Freitas ${ }^{\dagger}$ \\ André L. Morelato França ${ }^{\dagger}$
*SEL/EESC/USP
Av. Trabalhador São-carlense, 400, 13566-590, São Carlos, São Paulo, Brasil.
${ }^{\dagger}$ DSEE/FEEC/UNICAMP
Caixa Postal 6101, 13083-852,
Campinas, São Paulo, Brasil.

\section{RESUMO}

Antes de se proceder com a instalação de geração distribuída em redes de distribuição de energia elétrica, engenheiros de proteção devem projetar e parametrizar sistemas de proteção de forma eficiente para desconectar os geradores distribuídos dentro de um tempo pré-determinado, no caso de ocorrência de situações de ilhamento. Tanto o projeto quanto a avaliação de sistemas de proteção anti-ilhamento confiáveis exigem um estudo detalhado envolvendo numerosas simulações dinâmicas, as quais podem demandar muito tempo por parte dos especialistas de proteção. Este artigo tem por objetivo propor um conjunto de fórmulas para reduzir esse número de simulações dinâmicas. Tais fórmulas são capazes de determinar diretamente o comportamento dinâmico dos dispositivos anti-ilhamento mais empregados em geradores síncronos distribuídos: os relés baseados em medidas de freqüência. Elas

Artigo submetido em 31/07/2006

1a. Revisão em 11/10/2006

2a. Revisão em 16/05/2007

3a. Revisão em 24/01/2008

Aceito sob recomendação do Editor Associado

Prof. Denis Vinicius Coury são obtidas da solução analítica da equação de oscilação da máquina síncrona, juntamente com a solução das equações dos relés. Além disso, as curvas que relacionam o tempo de detecção com o desbalanço de potência ativa, conhecidas como curvas de desempenho, são empregadas para avaliar a exatidão das fórmulas. Tais curvas são obtidas tanto por simulação dinâmica quanto pelas fórmulas propostas, assim uma comparação abrangente pode ser realizada. Os dispositivos de proteção contra ilhamentos analisados neste trabalho são o relé de sub/sobre freqüência, o relé de taxa de variação de freqüência (em inglês, $R O C O F$ relay - Rate Of Change Of Frequency relay) e o relé de deslocamento de fase ou "salto de vetor" (em inglês Vector Surge, Vector Shift ou Voltage Jump relay).

PALAVRAS-CHAVE: geração distribuída, detecção de ilhamento, máquinas síncronas, proteção.

\begin{abstract}
Prior to the installation of distributed generation in distribution networks, protection engineers must design and adjust efficiently protection systems to disconnect all distributed
\end{abstract}


generators within acceptable time frame in case of islanding occurrences. Designing and evaluating reliable protection systems require numerous repeated dynamic simulations, which may be very time consuming. This paper aims to reduce the number of simulations necessary to design antiislanding protection of distributed generators by proposing a set of formulas that determine directly the dynamic behavior of the most employed anti-islanding devices in synchronousbased distributed generation: frequency-based relays. Such formulas are derived from the solution of the synchronous machine and relays equations. Moreover, the detection time versus active power imbalance curves, known as performance curves, are employed to evaluate the accuracy level of these formulas. These curves are obtained by non-linear dynamic simulations as well as by the proposed formulas, thus a thorough comparison can be done. The frequency-based relays analyzed are: under and over-frequency relays, rate of change of frequency relays (ROCOF relays) and vector surge or vector jump relays (VS relays).

KEYWORDS: distributed generation, islanding detection, synchronous machines, protection.

\section{INTRODUÇÃO}

A instalação de geradores de pequeno e médio portes em redes de distribuição e de subtransmissão de energia elétrica fato conhecido como geração distribuída - necessariamente deve ser acompanhada de uma série de estudos técnicos para garantir a operação segura, confiável e eficiente de todo o sistema elétrico, sobretudo após a ocorrência de curtos-circuitos ou contingências. Dentro desse conjunto de estudos técnicos, destacam-se aqueles necessários para ajustar os dispositivos de proteção instalados no ponto de conexão entre os geradores distribuídos e o sistema da concessionária. Para tanto, as concessionárias de energia estabelecem alguns requisitos técnicos a serem satisfeitos pelo proprietário do gerador distribuído. Um destes requisitos determina que o sistema de proteção do gerador deva ser capaz de detectar rapidamente uma situação de ilhamento.

O ilhamento ocorre quando uma parte da rede de distribuição torna-se eletricamente isolada da fonte de energia principal (subestação), mas continua a ser energizada por geradores distribuídos conectados no subsistema isolado. Tipicamente, recomenda-se desligar todos os geradores distribuídos tão logo ocorra uma situação de ilhamento (CIGRÉ Working Group 37.23, 1999; CIRED Working Group 4, 1999; Jenkins et alii, 2000; IEEE Standards Coordinating Committee 21,2003$)$. As principais implicações da não detecção do ilhamento e, por conseguinte da não desconexão dos geradores ilhados são (Reis Filho, 2002; Walling e Miller, 2002):

- a segurança das equipes de manutenção da concessio- nária, assim como dos consumidores em geral, pode ser colocada em risco devido a áreas que continuam energizadas sem o conhecimento da concessionária.

- a qualidade da energia fornecida para os consumidores na rede ilhada está fora do controle da concessionária, embora ela ainda seja a responsável legal por este item.

- a coordenação do sistema de proteção da rede ilhada pode deixar de operar satisfatoriamente devido à redução drástica dos níveis de curto-circuito na rede ilhada.

- o sistema ilhado pode apresentar um aterramento inadequado devido à perda de conexão com a concessionária.

- no instante de reenergização da rede o gerador pode estar fora de sincronismo, levando a sérios danos ao mesmo e aos demais componentes do sistema elétrico.

Embora a literatura técnica apresente diversos métodos de detecção de ilhamento (Xu et alii, 2004), até o momento os relés baseados em medidas de frequiência são reconhecidos pela indústria de energia elétrica como os métodos mais simples e eficazes para detectar esse problema. Logo, são também os métodos mais difundidos. No entanto, é bem reconhecido que esses dispositivos podem falhar caso o desbalanço de potência ativa no subsistema ilhado seja pequeno. Para definir os ajustes desses relés ou verificar se os mesmos são adequados em um determinado esquema de proteção anti-ilhamento, engenheiros de proteção necessitam realizar análises detalhadas através de numerosas simulações dinâmicas. Várias condições operativas do sistema elétrico são simuladas a fim de se determinar o ajuste mais adequado do dispositivo de proteção, baseando-se no comportamento dinâmico da grandeza de interesse. Portanto, essas análises podem demandar muito tempo. Com o objetivo de tornar essas análises mais rápidas e objetivas, este trabalho propõe métodos práticos e sistemáticos capazes de determinar diretamente o desempenho dinâmico dos relés baseados em medidas de freqüência e conseqüentemente, auxiliar na definição e verificação de seus ajustes. Tais métodos envolvem um conjunto de fórmulas desenvolvidas a partir da solução analítica das equações da máquina síncrona e dos relés. Para avaliar a exatidão das fórmulas propostas, emprega-se a metodologia das curvas de desempenho (Vieira Jr. et alii, 2005), as quais são obtidas utilizando-se as fórmulas aqui propostas, bem como repetidas simulações dinâmicas usando modelos detalhados para representar os vários componentes das redes de distribuição de energia elétrica. Os resultados mostram que as fórmulas analíticas permitem determinar com boa precisão o comportamento dinâmico dos relés, diminuindo consideravelmente o número de simulações necessárias durante o estágio de projeto/parametrização desses sistemas de proteção. Os relés analisados neste trabalho são o relé de sub/sobrefreqüência convencional, o relé de taxa de variação 
de frequiência (relé tipo $d f / d t$ ou rate of change of frequency relay) e o relé de deslocamento de fase ou "salto de vetor" (vector surge relay ou vector jump relay).

Este trabalho está organizado como segue. Na Seção 2, os princípios de funcionamento desses relés são brevemente discutidos. Um conjunto de fórmulas analíticas para cada tipo de relé investigado neste trabalho é desenvolvido e validado na Seção 3, em que para verificar a precisão das fórmulas, as curvas de desempenho dos relés obtidas via simulação e fórmulas são comparadas. A Seção 4 apresenta a dedução de fatores de correção para as fórmulas analíticas quando as cargas do sistema elétrico são dependentes da tensão. Desses fatores de correção, originam-se as fórmulas empíricas. As principais conclusões obtidas são apresentadas na Seção 5.

\section{PRINCÍPIO DE FUNCIONAMENTO DOS RELÉS BASEADOS EM MEDIDAS DE FREQÜÊNCIA}

Os relés baseados em medidas de freqüência utilizados neste trabalho foram detalhadamente descritos em Vieira Jr. et alii (2005) e nesta seção apenas seus diagramas esquemáticos serão apresentados para facilitar a compreensão do desenvolvimento das fórmulas.

\subsection{Relés de Sub/Sobrefreqüência}

O esquema de funcionamento de um relé de sub/sobrefreqüência é apresentado na Figura 1. O sinal de frequiência $(f)$ a ser usado pelo relé é determinado considerando-se uma janela de medida sobre, no mínimo, um ciclo da freqüência da tensão e, em seguida, esse sinal passa por um filtro com constante de tempo $T_{a}$, com a finalidade de eliminar transitórios de alta freqüência.

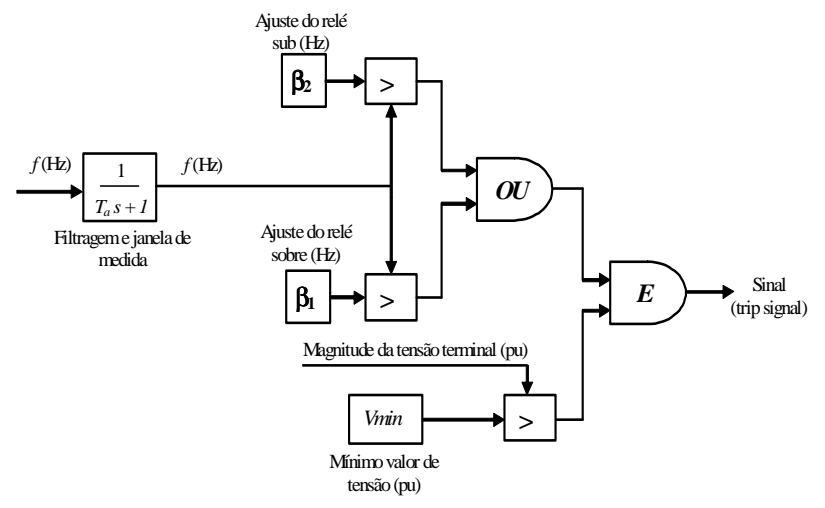

Figura 1: Diagrama de blocos de um relé de sub/sobrefreqüência.
A freqüência medida é comparada com os ajustes de sub e sobrefrequiência do relé, $\beta_{2}$ e $\beta_{1}$,respectivamente, e caso o valor medido seja superior ao ajuste de sobrefreqüência ou inferior ao ajuste de subfreqüência, o relé envia um sinal para o disjuntor abrir e desconectar o gerador síncrono. Os relés de frequiência podem também ser equipados com um elemento que bloqueia o seu funcionamento se a magnitude da tensão terminal estiver abaixo de um determinado valor $\left(V_{\text {min }}\right)$. Isso usualmente é adotado para evitar a operação do relé durante a partida do gerador, por exemplo. Muitas vezes, tais relés são operados de forma temporizada.

Relés de freqüência empregados na proteção da interligação entre o gerador distribuído e a concessionária podem ser ajustados para realizar basicamente as seguintes funções de proteção (Vieira et alii, 2006):

- Detectar ilhamento dentro do tempo requerido pelas normas da concessionária.

- Proteger os geradores distribuídos contra variações excessivas de freqüência provenientes do sistema de transmissão, porém com atuação temporizada para permitir que os mesmos auxiliem na recuperação do sistema elétrico após contingências.

Esse tipo de relé é fortemente dependente do desbalanço de potência ativa, logo ele pode não operar dentro do tempo requerido pela concessionária, caso a geração e a carga do subsistema ilhado estejam em equilíbrio. Isso é particularmente preocupante quando o mesmo é usado para detectar ilhamentos, pois se o desbalanço de potência ativa na rede ilhada for pequeno, o sistema pode permanecer isolado da concessionária por um longo período de tempo. Para minimizar esse problema, é comum usar relés de taxa de variação de frequiência, conforme abordado a seguir.

\subsection{Relés de Taxa de Variação de Freqüência}

O diagrama esquemático de um relé de taxa de variação de frequiência é mostrado na Figura 2. A taxa de variação da freqüência é calculada considerando-se uma janela de medida de alguns ciclos sobre a forma de onda da tensão, usualmente entre 2 e 50 ciclos (Jenkins et alii, 2000). Esse sinal é então processado por filtros e o sinal resultante é usado pelo relé para decidir se o disjuntor deve ser aberto ou não. Se o valor absoluto da taxa de variação da frequiência for maior que o ajuste do relé $(\beta)$, um sinal é imediatamente enviado para o disjuntor do gerador comandando sua abertura. Ajustes típicos desses relés instalados nos sistemas de distribuição e usados para a detecção de ilhamentos estão na faixa de 0,10 a 2,00 Hz/s (Jenkins et alii, 2000). Eles ainda são equi- 


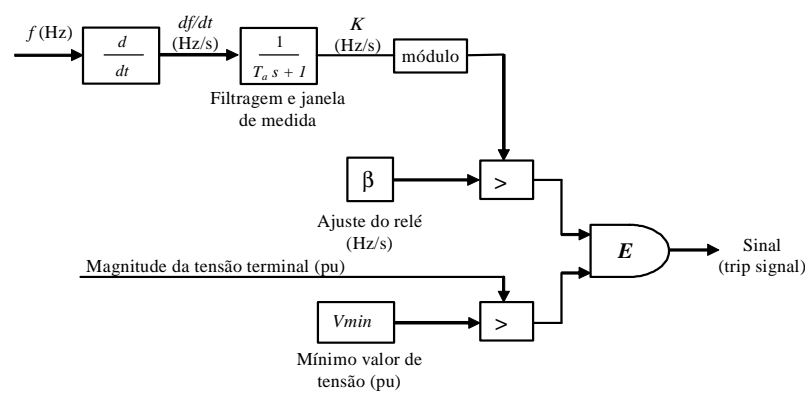

Figura 2: Diagrama esquemático de um relé de taxa de variação de frequiência (relé df/dt).

pados com um elemento que bloqueia o funcionamento do relé se a magnitude da tensão terminal estiver abaixo de um determinado valor $\left(V_{\min }\right)$.

Relés de taxa de variação de freqüência são muito empregados em esquemas de detecção de ilhamento (Jenkins et alii, 2000), pois podem acelerar a detecção do problema caso a frequiência varie lentamente. No entanto, eles também estão sujeitos a falhas caso o desbalanço de potência ativa seja pequeno (Vieira Jr et alli, 2005), assim como ocorre com os relés de freqüência.

\subsection{Relés de Deslocamento de Fase}

O diagrama esquemático de um relé de deslocamento de fase é mostrado na Figura 3. Se a variação do ângulo da tensão medida pelo relé for maior do que um ângulo de referência $\beta$ previamente ajustado no dispositivo, um sinal é imediatamente enviado pelo relé para o disjuntor desconectar o gerador síncrono. Tipicamente, relés de deslocamento de fase são ajustados em valores entre 2 e 20 graus (Jenkins et alii, 2000). Tais relés também são equipados com um elemento que bloqueia o funcionamento do relé se a magnitude da tensão terminal estiver abaixo de um determinado valor $\left(V_{\min }\right)$.

Para definir fórmulas analíticas para os relés de deslocamento de fase é essencial o entendimento de seu princípio de funcionamento. Os relés de deslocamento de fase existentes no mercado medem a duração de um ciclo elétrico e uma nova medida é iniciada no instante em que a forma de onda da tensão terminal muda de um valor negativo para um valor positivo. A duração do ciclo atual (onda medida) é comparada com a duração do último ciclo medido (referência). Em uma situação de ilhamento, a duração do ciclo é mais longa ou curta, dependendo se há déficit ou excesso de potência ativa na rede ilhada, como mostrado na Figura 4. Essa variação da duração do ciclo resulta em uma variação proporcional do ângulo da tensão terminal $\Delta \theta$. Na Figura 4, o ilhamento ocorre no instante $A ; T$ é o período medido pelo relé e $\omega$ é a freqüência angular do sinal de tensão.

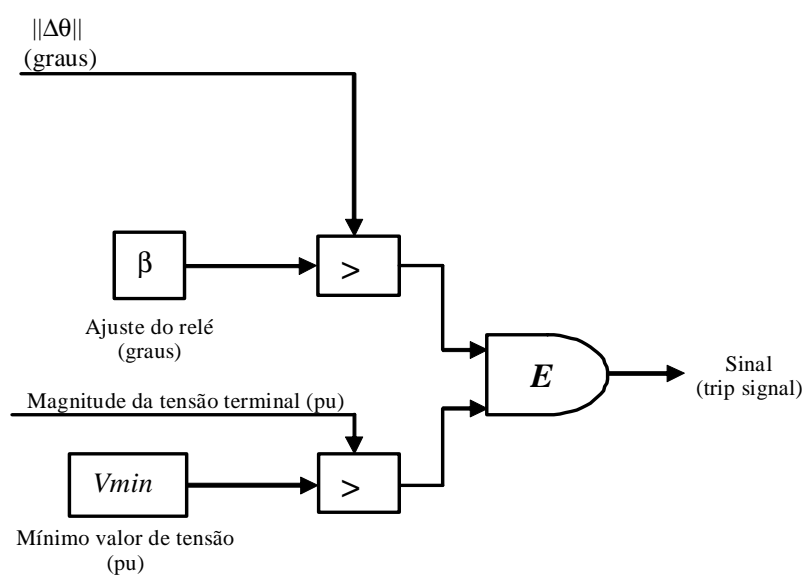

Figura 3: Diagrama esquemático do relé deslocamento de fase.

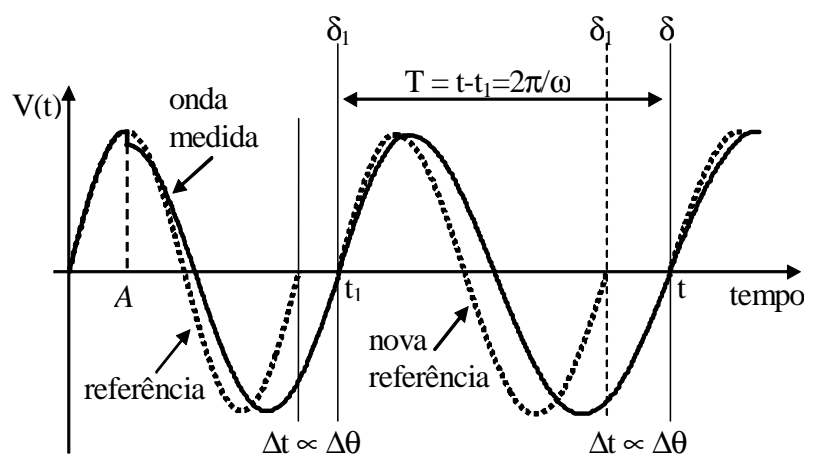

Figura 4: Deslocamento de fase da tensão terminal.

Esse tipo de dispositivo também é muito usado para a detecção de ilhamento (Jenkins et alii, 2000). No entanto, como a variação do ângulo da tensão terminal está associada ao desbalanço de potência ativa da rede ilhada, ele também pode falhar caso esse desbalanço seja pequeno (Vieira Jr et alli, 2005). Em Vieira Jr et alii (2005) mostra-se que seu desempenho é muito similar ao desempenho dos relés de freqüência. Logo, ambos estão sujeitos às mesmas limitações.

\section{FÓRMULAS ANALÍTICAS}

No sistema elétrico apresentado na Figura 5, em regime permanente, a potência mecânica $P_{M}$ (admitida igual à potência elétrica gerada $P_{G S}$ em pu) do gerador síncrono está equilibrada com a potência elétrica $P_{L}$ consumida pela carga $L$ e com a potência elétrica $P_{S I S}$ fornecida (ou consumida) pela rede elétrica. Portanto, a velocidade $\omega$ e o ângulo $\delta$ do rotor do gerador síncrono são constantes. Depois da abertura do disjuntor $D J$, o desbalanço de potência ativa $\Delta P$, cuja magnitude é igual a $P_{S I S}$, causa transitórios no gerador síncrono. Seu comportamento dinâmico pode ser determinado usando 


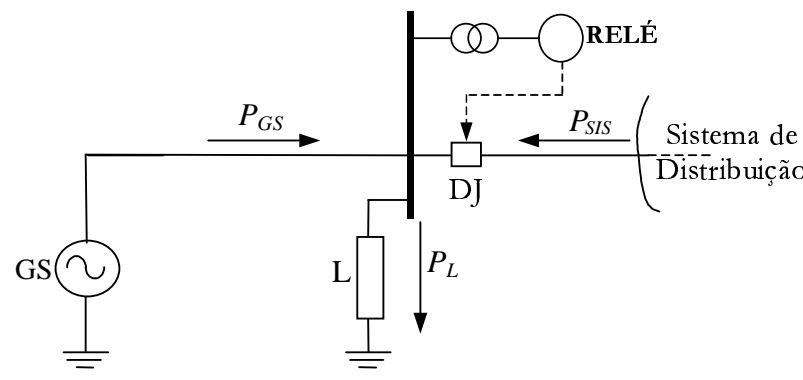

Figura 5: Diagrama esquemático de um gerador síncrono (GS) equipado com um relé baseado em medida de frequiência operando em paralelo com a concessionária.

a equação de oscilação da máquina síncrona. No desenvolvimento matemático a seguir, admite-se que as cargas são representadas pelo modelo de potência constante e que o gerador é representado pelo modelo clássico (Kundur, 1994). A equação de oscilação do gerador síncrono é dada por:

$$
\left\{\begin{array}{l}
\frac{2 H}{\omega_{0}} \frac{d \omega}{d t}=P_{M}-P_{L}=-P_{S I S}=\Delta P \\
\frac{d \delta}{d t}=\omega-\omega_{0}
\end{array}\right.
$$

em que $H$ é a constante de inércia do gerador, $\omega_{0}=2 \pi f_{0}$ é a velocidade síncrona, $f_{0}$ é a frequiência nominal do sistema e as demais variáveis já foram definidas previamente. Essa equação será empregada para representar a dinâmica do gerador nas seções seguintes.

\subsection{Relé de Sub/Sobrefreqüência}

A velocidade do rotor do gerador pode ser obtida solucionando-se a equação (1) como segue:

$$
\omega=\frac{\omega_{0} \cdot \Delta P}{2 H} t+\omega_{0}
$$

O comportamento da velocidade angular no tempo pode ser representado por $\omega=\omega_{0}+\Delta \omega$. Substituindo tal representação na equação (2), tem-se:

$$
\omega_{0}+\Delta \omega=\frac{\omega_{0} \cdot \Delta P}{2 H} t+\omega_{0} \Rightarrow \Delta \omega=\frac{\omega_{0} \cdot \Delta P}{2 H} t
$$

sendo: $\omega=2 \pi f$. Portanto, segue-se:

$$
\Delta f=\beta=\frac{f_{0} \cdot \Delta P}{2 H} t
$$

A equação (4) fornece a relação entre o desvio de frequiência na rede ilhada, o tempo de detecção e o desbalanço de potência ativa. Para simplificar, admite-se que o ajuste desse relé é um valor correspondente ao desvio em torno de $60 \mathrm{~Hz}$, por exemplo, um ajuste igual a $\pm 1,5 \mathrm{~Hz}$ significa $58,5 \mathrm{~Hz}$ para casos de subfreqüência e $61,5 \mathrm{~Hz}$ para sobrefrequiência. Relés de freqüência disponíveis comercialmente têm um tempo de mínima operação referente aos atrasos no circuito de medição e processamento do algoritmo dos mesmos. Por meio de pesquisas em catálogos de diversos fabricantes de relés de freqüência, admitiu-se $80 \mathrm{~ms}$ como atraso inerente do relé. Logo, para efeito de desenvolvimento das fórmulas, esse tempo será representado por $\Delta t$. Portanto, o tempo total de detecção do relé $\left(t_{d}\right)$ é composto pelo tempo de detecção do evento ( $t$ na equação (4)) mais o tempo de mínima operação, resultando em $t_{d}=t+\Delta t$. Portanto, $t=t_{d}-\Delta t$.

A expressão (4) também pode ser solucionada para o desbalanço de potência ativa $\Delta P$ já substituindo $t$ por $t_{d}-\Delta t$, como segue:

$$
\Delta P=\frac{2 H \cdot \beta}{f_{0} \cdot\left(t_{d}-\Delta t\right)}
$$

Solucionando tal expressão para o tempo $t_{d}$, obtém-se:

$$
t_{d}=\frac{2 H \cdot \beta}{f_{0} \cdot \Delta P}+\Delta t
$$

onde $\beta$ é o ajuste do relé. Como mencionado anteriormente, relés de frequiência podem ser ajustados com estágios temporizados. Neste caso, tem-se:

$$
t_{d}=\frac{2 H \cdot \beta}{f_{0} \cdot \Delta P}+T_{\text {set }}+\Delta t
$$

sendo $T_{\text {set }}$ o ajuste do elemento temporizado. Desse modo, a equação (4) devidamente modificada para contemplar o atraso inerente ao relé, juntamente com as expressões (5), (6) e (7) podem ser empregadas para avaliar o desempenho de relés de freqüência e, conseqüentemente, auxiliar na seleção do ajuste mais adequado.

\subsection{Relé de Taxa de Variação de Freqüên- cia}

Solucionando a equação (1), a taxa de variação da freqüência pode ser calculada por:

$$
\frac{d f}{d t}=\frac{1}{2 \pi} \frac{d \omega}{d t}=\frac{f_{0}}{2 H} \Delta P
$$

De acordo com a equação (8), a taxa de variação da frequiência é proporcional ao desbalanço de potência ativa. Na Fi- 
gura 2, o sinal $K$ que é de fato utilizado para disparar o relé é processado por filtros, os quais podem ser representados por funções de transferência de primeira ordem. Assim, o sinal utilizado pelo relé tipo $d f / d t$ pode ser calculado pela expressão (9), a qual está representada no domínio da freqüência:

$$
K(s)=\frac{f_{0} \Delta P(s)}{2 H \cdot\left(T_{a} s+1\right)}=\frac{f_{0}}{2 H \cdot\left(T_{a} s+1\right)} \cdot \frac{\Delta P}{s}
$$

em que $T_{a}$ é a constante de tempo dos filtros e da janela de medição do relé. $\Delta P(s)$ pode ser representado por uma função degrau, pois no instante $\mathrm{t}=0 \mathrm{~s}$, o gerador estará submetido a uma variação de carga de amplitude $\Delta P$. Logo, $\Delta P(s)$ $=\Delta P / s . \quad$ Em t $=0 \mathrm{~s}$, tem-se $K(0)=0$ porque o sistema está operando em regime permanente. Portanto, a solução da equação (9) no domínio do tempo é dada aplicando a transformada inversa de Laplace em (9), resultando (10):

$$
K=\frac{f_{0} \Delta P}{2 H}\left(1-e^{\frac{-t}{T_{a}}}\right)
$$

O relé de taxa de variação de freqüência atua se o valor do sinal $K$ for maior que o valor $\beta$ ajustado no relé. Além disso, esse relé também tem o tempo de mínima operação $(\Delta t)$, tal como mencionado anteriormente para o relé de freqüência. Neste caso, admite-se 130 ms como tempo de mínima operação - valor médio obtido de catálogos de diversos fabricantes de relés. Assim, o tempo de detecção da expressão (10) deve ser substituído por $t=t_{d}-\Delta t$. Imediatamente antes da atuação do relé, ambos os sinais são iguais e assim é possível substituir $K$ por $\beta$ em (10), resultando:

$$
\beta=\frac{f_{0} \Delta P}{2 H}\left(1-e^{\frac{-\left(t_{d}-\Delta t\right)}{T_{a}}}\right)
$$

Adicionalmente, solucionando a equação (11) para desbalanço de potência ativa $\Delta P$ e para o tempo $t_{d}$, têm-se as equações (12) e (13), respectivamente:

$$
\begin{gathered}
\Delta P=\frac{2 H}{f_{0}} \beta\left(1-e^{\frac{-\left(t_{d}-\Delta t\right)}{T_{a}}}\right)^{-1} \\
t_{d}=-T_{a} \ln \left(1-\frac{2 H}{f_{0} \Delta P} \beta\right)+\Delta t
\end{gathered}
$$

Os ajustes desse tipo de relé também podem ser temporizados. Logo, para considerar uma temporização $T_{\text {set }}$, tem-se:

$$
t_{d}=-T_{a} \ln \left(1-\frac{2 H}{f_{0} \Delta P} \beta\right)+T_{\text {set }}+\Delta t
$$

Desse modo, as equações (11) a (14) podem ser empregadas para avaliar o desempenho de relés tipo $d f / d t$ e, conseqüentemente, auxiliar na seleção do ajuste mais adequado.

\subsection{Relé de Deslocamento de Fase}

O ângulo do rotor do gerador pode ser obtido da equação (1) como segue:

$$
\delta=\frac{\omega_{0} \Delta P}{4 H} t^{2}+\delta_{0}
$$

Considerando a medida ciclo-a-ciclo realizada pelo relé mostrada na Figura 4, a seguinte variação de ângulo pode ser calculada:

$$
\begin{aligned}
& \Delta \delta=\delta-\delta_{1}=\left(\frac{\omega_{0} \Delta P}{4 H} t^{2}+\delta_{0}\right)-\left(\frac{\omega_{0} \Delta P}{4 H} t_{1}^{2}+\delta_{0}\right)= \\
& =\frac{\omega_{0} \Delta P}{4 H} \cdot\left(2 t-\left(t-t_{1}\right)\right) \cdot\left(t-t_{1}\right)
\end{aligned}
$$

Na Figura 4, verifica-se que $\left(t-t_{1}\right)$ é, de fato, a duração do ciclo atual, a qual pode ser determinada aproximadamente solucionando-se a equação (1) para a velocidade do rotor e depois para o período do ciclo, obtendo-se:

$$
T=t-t_{1}=\frac{1}{f}=\frac{2 \pi}{\omega}=\frac{2 \pi}{\frac{\omega_{0} \Delta P}{2 H} t+\omega_{0}}
$$

Substituindo $\left(t-t_{1}\right)$ em (16) por (17) e considerando a variação do ângulo do rotor $\Delta \delta$ igual ao ajuste do relé $\beta$, a seguinte relação pode ser obtida:

$$
\beta=\frac{K}{2} \cdot\left(2 t-\frac{2 \pi}{K t+\omega_{0}}\right) \cdot \frac{2 \pi}{K t+\omega_{0}}
$$

sendo $K=\omega_{0} \Delta P / 2 H$. Reorganizando a equação (18) obtémse:

$\underbrace{K^{2} \cdot(\beta-2 \pi)}_{A} t^{2}+\underbrace{2 \omega_{0} K \cdot(\beta-\pi)}_{B} t+\underbrace{\omega_{0}^{2} \beta+2 \pi^{2} K}_{C}=0$

Esta é uma equação de segunda ordem, cujos coeficientes são:

- $A=K^{2}(\beta-2 \pi)<0$, se $\beta<2 \pi$

- $B=2 \omega_{0} K(\beta-\pi)<0$, se $\beta<\pi$

- $C=\omega_{0}^{2} \beta+2 \pi^{2} K>0$ 
Para os ajustes típicos de relés de deslocamento de fase as soluções de (19) são números reais. Porém, somente as soluções positivas são de interesse, as quais podem ser calculadas por:

$$
t=\frac{-\left(2 \omega_{0} K \cdot(\beta-\pi)\right)-\sqrt{D_{1}}}{2 K^{2} \cdot(\beta-2 \pi)}
$$

sendo: $D_{1}=\left(2 \omega_{0} K(\beta-\pi)\right)^{2}-4 K^{2}(\beta-2 \pi)\left(\omega_{0}^{2} \beta+\right.$ $\left.2 \pi^{2} K\right)$. A equação (20) pode ser solucionada para o desbalanço de potência $\Delta P$ como segue:

$$
\Delta P=\left(\frac{2 H}{\omega_{o}}\right) \cdot\left(\frac{-2 \cdot\left(\pi^{2}+\omega_{0} \cdot t \cdot(\beta-\pi)\right)-\sqrt{D_{2}}}{2 t^{2} \cdot(\beta-2 \pi)}\right)
$$

sendo: $D_{2}=\left(2\left(\pi^{2}+\omega_{0} t(\beta-\pi)\right)\right)^{2}-4\left(t^{2}(\beta-\right.$ $\left.2 \pi)\left(\omega_{0}^{2} \beta\right)\right)$. Assim, as equações (18), (20) e (21) podem ser empregadas para avaliar o desempenho de relés de deslocamento de fase, bem como auxiliar na seleção do ajuste mais adequado.

\subsection{Utilidade das Fórmulas Analíticas}

As fórmulas analíticas desenvolvidas anteriormente para os relés baseados em medidas de frequiência abordados neste trabalho podem ser úteis nas seguintes situações:

- Se o desbalanço de potência ativa $\Delta P$ e o tempo requerido de detecção são conhecidos, pode-se determinar o ajuste do relé utilizando-se (4) modificada, (11) ou (18), dependendo do tipo de relé sob análise.

- Se o tempo requerido de detecção e o ajuste do relé são conhecidos, pode-se determinar qual o valor mínimo necessário de desbalanço de potência $\Delta P$ para que o relé atue utilizando-se (5), (12) ou (21), dependendo do tipo de relé sob análise.

- Se o desbalanço de potência ativa $\Delta P$ e o ajuste do relé são conhecidos, pode-se determinar o tempo que o relé levará para detectar a situação de ilhamento utilizandose (6), (13) ou (20), dependendo do tipo de relé.

\subsection{Validação das Fórmulas Analíticas}

\subsubsection{Curvas de Desempenho de Relés Baseados em Medidas de Freqüência}

Para validar o desenvolvimento matemático descrito anteriormente, empregam-se as curvas de desempenho do relé (Vieira Jr. et alii, 2005), que relacionam o tempo de detecção do relé com o desbalanço de potência ativa do sistema elétrico ilhado. Essas curvas são obtidas via simulação dinâmica e também usando as fórmulas previamente desenvolvidas. As análises consideram o sistema teste representado na Figura 6, que consiste de um sistema de subtransmissão de $132 \mathrm{kV}$ e $60 \mathrm{~Hz}$ com nível de curto-circuito de 1500 MVA alimentando um sistema de distribuição de 33 kV. Nesse sistema, há um gerador síncrono com capacidade de 30 MVA conectado na barra 5. Os componentes do sistema elétrico da Figura 6 foram representados por modelos trifásicos. Linhas de distribuição foram representadas por uma impedância série $R L$. Transformadores foram modelados usando o circuito $T$. O gerador síncrono foi representado por um modelo de sexta ordem na referência $d q 0$ do rotor (Kundur, 1994). O gerador foi considerado equipado com um regulador automático de tensão, o qual foi representado pelo modelo IEEE Tipo 1 (Kundur, 1994). A potência mecânica do gerador foi considerada constante, pois o intervalo de simulação utilizado é pequeno (até 1 segundo). Nas simulações, considera-se que o disjuntor $D J$ na barra 2 abre em $\mathrm{t}=0,25$ segundo, permanecendo aberto até o fim da simulação. Assim, o desbalanço de potência ativa inicial no sistema ilhado é igual à potência ativa fornecida pela subestação no instante de ilhamento. $\mathrm{O}$ tempo total de simulação é 1,25 segundo. Portanto, se o ilhamento não é detectado em 1,0 segundo pelo relé instalado na barra 5, é considerado que o dispositivo falha neste caso. Diferentes cenários de desbalanço de potência ativa são obtidos variando-se, gradualmente, a potência ativa fornecida pelo gerador ou a carga total do sistema de 0 a 1 pu referido à capacidade nominal da máquina (30 MVA). Para cada valor de desbalanço de potência ativa, uma simulação dinâmica é realizada para determinar o tempo de detecção do ilhamento e posteriormente as curvas de desempenho.

\subsubsection{Curvas de Desempenho Obtidas via Simula- ção e Fórmulas}

As curvas de desempenho dos relés analisados anteriormente foram obtidas pelas seguintes expressões:

- Relé de sub/sobrefrequiência: equação (6) para ajustes instantâneos e (7) para ajustes temporizados;

- Relé de taxa de variação de freqüência: equação (13)

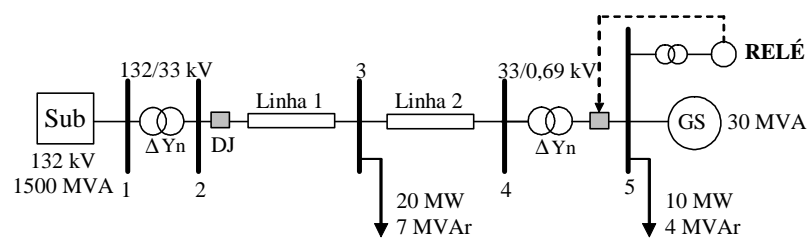

Figura 6: Diagrama unifilar do sistema teste. 
para ajustes instantâneos e (14) para temporizados;

- Relé de deslocamento de fase: equação (20).

A Figura 7 mostra as curvas de desempenho obtidas por simulação dinâmica e pelas fórmulas analíticas para os ajustes típicos dos relés baseados em medidas de frequiência. Se considerarmos 500 ms como o tempo máximo necessário para a detecção de ilhamento, determina-se o desbalanço crítico de potência ativa de cada ajuste pela intersecção da linha horizontal que representa esse tempo com a curva de desempenho. Esse valor de desbalanço determina o mínimo desbalanço de potência ativa capaz de ativar o relé dentro do tempo requisitado pela concessionária (Vieira Jr. et alii, 2005). Assim, ele pode ser usado como uma medida para avaliar a capacidade de detecção de ilhamento de determinado ajuste, considerando o tempo de detecção requerido pela concessionária.

A Figura 8 apresenta os desbalanços críticos de potência ativa calculados por meio das simulações e das fórmulas para cada ajuste dos relés da Figura 7. Observa-se em todos os casos uma boa precisão entre os resultados obtidos pelas fórmulas e por simulação, pois os níveis de desbalanço crítico de potência muito próximos. Destaca-se que as fórmulas são obtidas usando o modelo clássico da máquina síncrona, enquanto que as simulações foram realizadas usando o modelo de sexta ordem do gerador e considerando o regulador automático de tensão.

A boa precisão das fórmulas analíticas também pode ser verificada quando ajustes temporizados são aplicados. Essa característica é mostrada na Figura 9 para os relés de sub/sobrefreqüência e de taxa de variação de freqüência, em que uma temporização de $100 \mathrm{~ms}$ foi aplicada em diversos ajustes dos relés.

Outros sistemas elétricos diferentes daquele apresentado na Figura 6 também foram testados e observou-se que a precisão das fórmulas analíticas foi mantida. Esses resultados não foram apresentados neste trabalho para que o mesmo não se tornasse muito extenso. Segundo a consideração das cargas do sistema teste da Figura 6 serem modeladas como potência constante, o desbalanço de potência ativa não varia após a ocorrência do ilhamento, visto que as cargas não dependem da tensão ou frequiência. No entanto, para cargas dependentes da tensão o desbalanço da potência ativa varia dinamicamente em função da tensão após o ilhamento, influenciando o desempenho de relés baseados em medidas de freqüência (Vieira Jr. et alii, 2005). Assim, uma análise mais detalhada das fórmulas analíticas para considerar cargas dependentes da tensão é apresentada na seção seguinte.

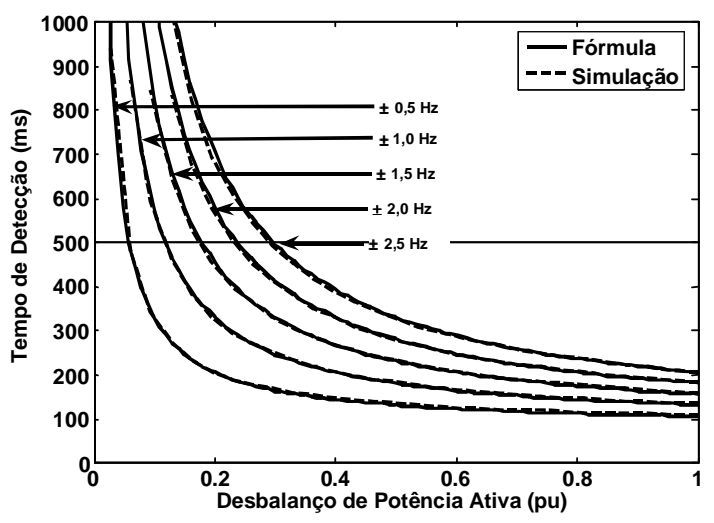

(a) Relé de sub/sobrefreqüência.

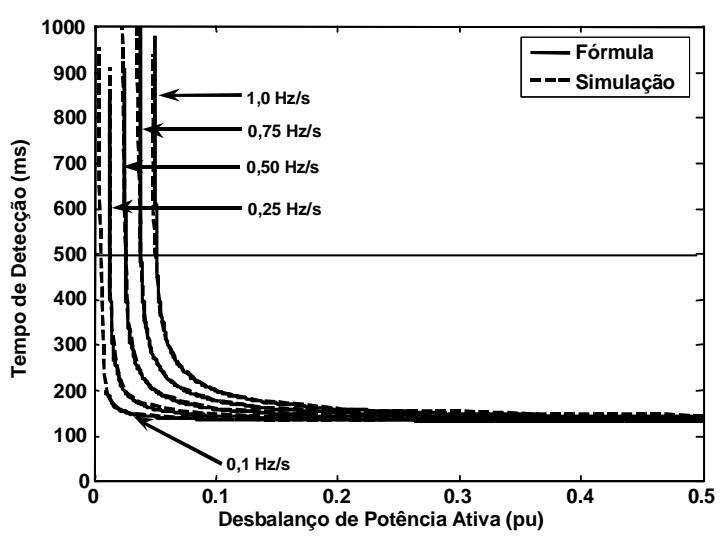

(b) Relé de taxa de variação de freqüência.

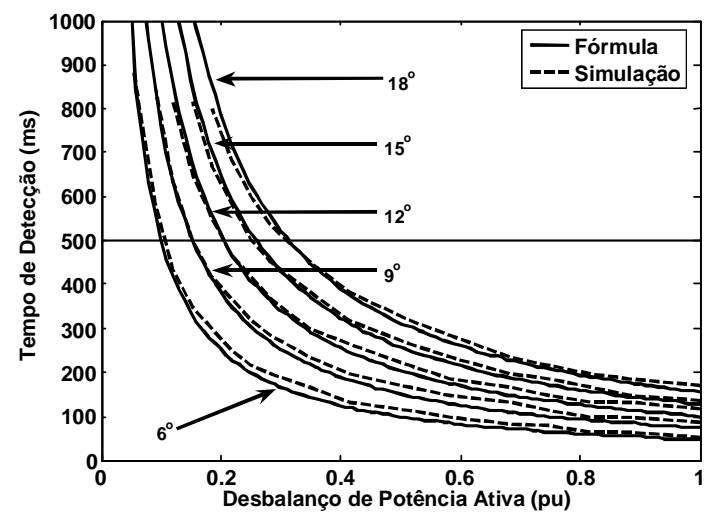

(c) Relé de deslocamento de fase.

Figura 7: Comparação do desempenho dos relés: fórmulas analíticas versus simulação.

\section{FÓRMULA EMPÍRICA PARA CASOS GENÉRICOS}

Na presença de cargas dependentes da tensão o desbalanço de potência ativa varia dinamicamente após a ocorrência do ilhamento, em razão da variação das tensões nodais. Tal va- 


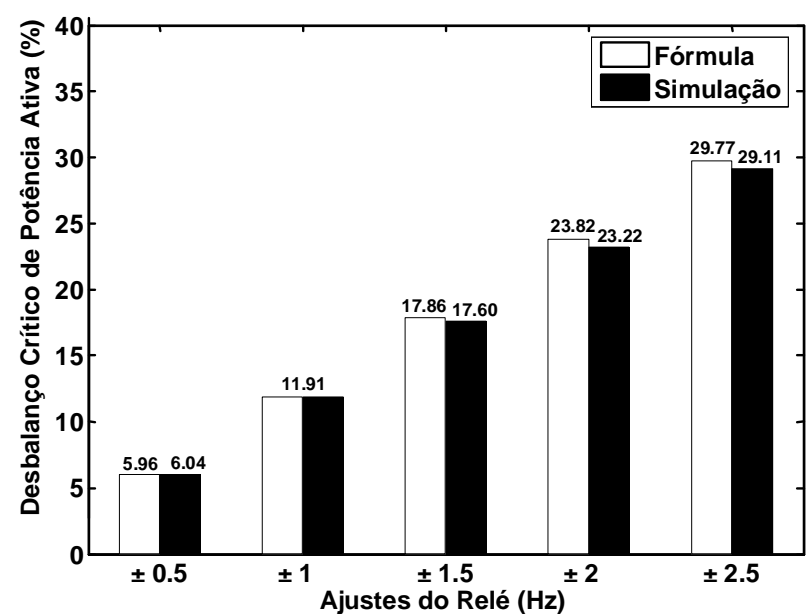

(a) Relé de sub/sobrefreqüência.

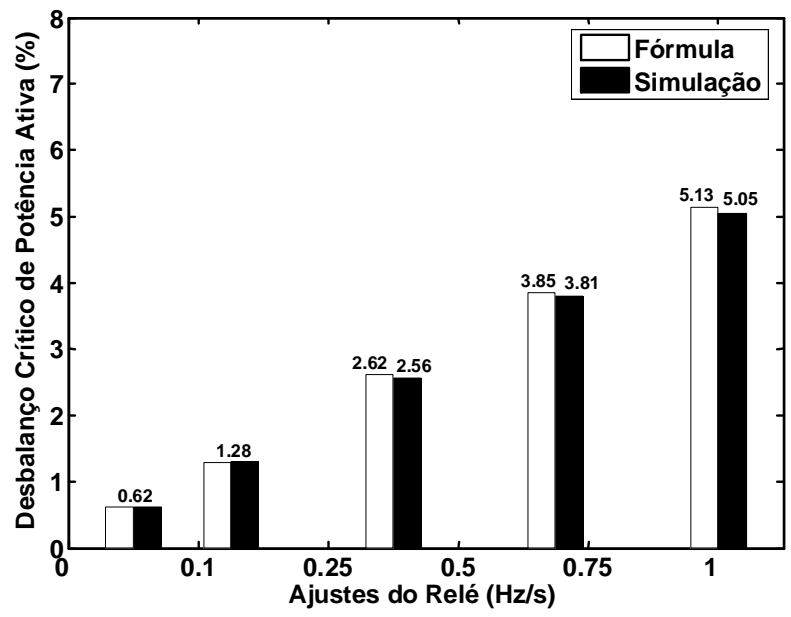

(b) Relé de taxa de variação de freqüência.

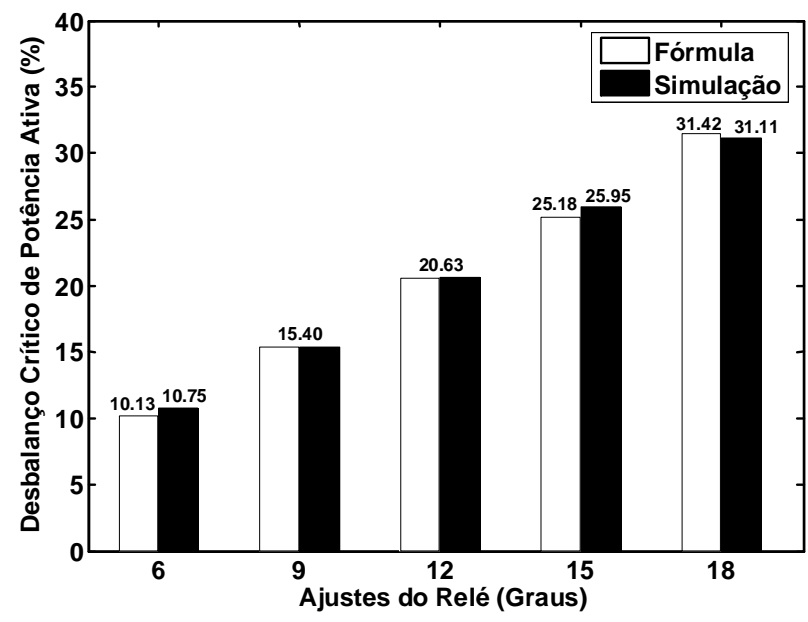

(c) Relé de deslocamento de fase.

Figura 8: Desbalanços críticos de potência ativa: fórmulas analíticas versus simulação.

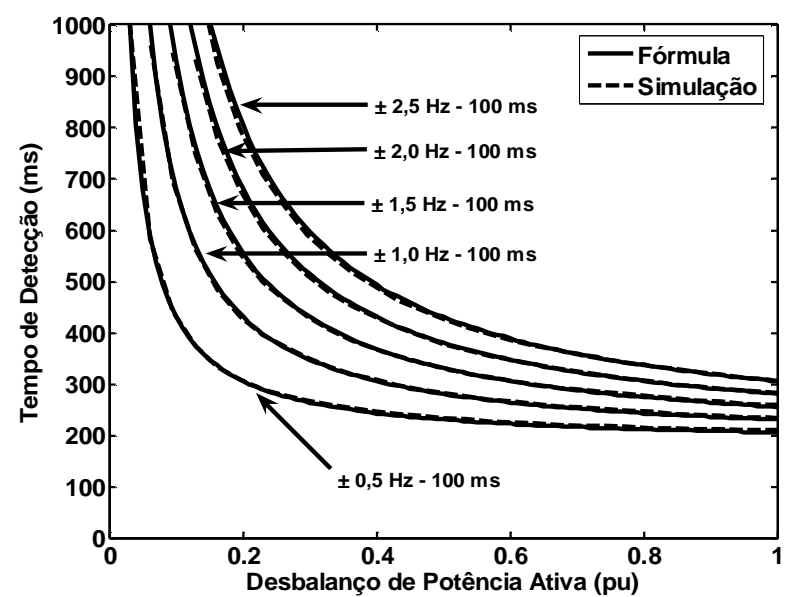

(a) Relé de sub/sobrefreqüência.

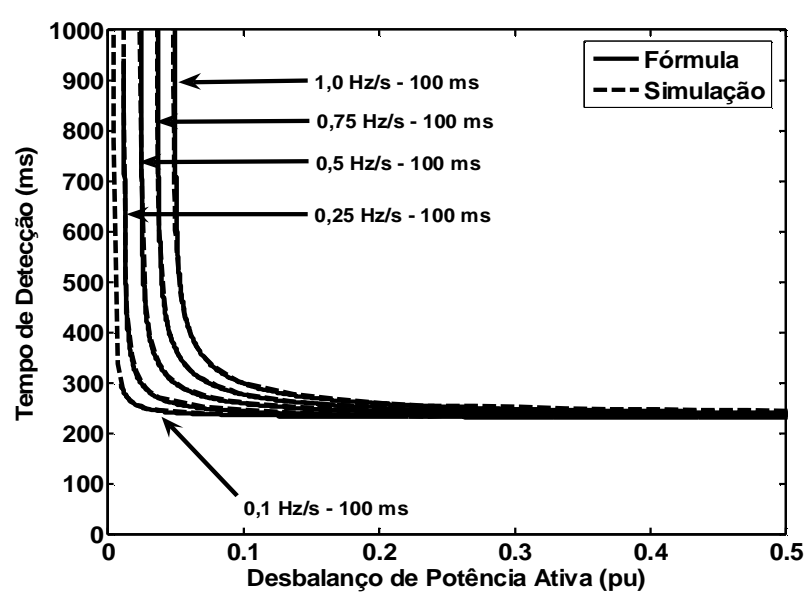

(b) Relé de taxa de variação de freqüência.

Figura 9: Comparação entre as fórmulas analíticas e simulação para ajustes temporizados.

riação depende tanto das características da rede quanto do gerador síncrono e também do ponto de operação do sistema elétrico. Visto que há diversos fatores envolvidos nessa variação, é difícil obter uma expressão analítica que determine, precisamente, o comportamento dinâmico da tensão após o ilhamento e, conseqüentemente, o comportamento do desbalanço de potência ativa. Dessa forma, nesta seção propõe-se uma fórmula empírica capaz de estimar o desbalanço de potência ativa após o ilhamento, baseando-se na observação de inúmeros casos simulados e considerando diferentes características das cargas do sistema elétrico. Os resultados originaram um fator de correção do desbalanço de potência ativa para cada tipo de relé baseado em medidas de freqüência empregado neste trabalho. As sub-seções seguintes apresentam o desenvolvimento das fórmulas empíricas para os relés de sub/sobrefrequiência, de taxa de variação de frequiência e de deslocamento de fase. 


\subsection{Relé de Sub/Sobrefreqüência}

Tipicamente, as cargas do sistema elétrico podem ser representadas por uma combinação dos modelos de potência, corrente e impedância constante (IEEE Task Force, 1993; Kundur, 1994). Os componentes de potência ativa das cargas podem ser representados pela seguinte expressão:

$$
P=P_{0}\left(\frac{V}{V_{0}}\right)^{n p}
$$

em que $P$ é a potência ativa consumida pela carga (em pu), $P_{0}$ é a potência ativa nominal da carga (em pu), $V$ é a tensão nodal (em pu) e $V_{0}$ é a tensão nominal da carga (em pu). $\mathrm{O}$ expoente $n_{p}$ representa a relação entre a potência ativa e a tensão nodal, sendo que seu valor, usualmente, está entre 0 e 2 (IEEE Task Force, 1993; Kundur, 1994). np igual a 0,1 ou 2 representa carga tipo potência constante, corrente constante ou impedância constante, respectivamente. Para aplicar a expressão (22) de forma a obter uma característica agregada da carga total do sistema, pode-se definir um índice $N P_{T}$ conforme segue:

$$
N P_{T}=\sum_{i=1}^{n b a r} \frac{P_{i}}{P_{T}} n_{p i}
$$

em que $P_{T}$ é a potência ativa total das cargas do sistema elétrico (em pu), nbar é o número de barras do sistema elétrico, $P_{i}$ é a potência ativa da carga (em pu) conectada ao nó $i$. Caso a $n p_{i}$ sejam atribuídos valores entre 0 e $2, N P_{T}$ também assumirá valores entre 0 e 2 . Adicionalmente, quanto maior o valor de $N P_{T}$ maior é a variação do desbalanço da potência ativa em função da tensão.

Baseando-se na observação de inúmeros casos realizados em diferentes sistemas elétricos e com diferentes geradores síncronos distribuídos, verificou-se que as maiores variações do desbalanço de potência ativa ocorreram na presença de cargas tipo impedância constante (Vieira Jr. et alii, 2005). Além disso, observou-se que essa variação permaneceu dentro da faixa de 10 a $30 \%$ em torno do valor de regime permanente. Assim, admitiu-se que o desbalanço de potência ativa sofre uma variação média de $20 \%$ após a ocorrência do ilhamento, na presença de cargas dependentes da tensão. Portanto, define-se um fator de correção do desbalanço de potência ativa, denominado $P_{f a c}$, o qual obedece à seguinte restrição:

$$
1,2 \geq P_{f a c} \geq 0,8
$$

Note que o fator de correção do desbalanço de potência ativa pode ser usado tanto para os casos em que o desbalanço de potência diminui após o ilhamento, quanto para as situações em que o mesmo aumenta. Sabendo que os valores de $N P_{T}$ variam entre 0 e 2 , e utilizando-se de interpolação linear, obtém-se a expressão (25), a qual relaciona o índice $N P_{T}$ com o fator de correção $P_{f a c}$ :

$$
P_{f a c}=1 \pm \frac{N P_{T} \cdot 0,2}{2}
$$

O sinal " \pm " é determinado de acordo com a combinação de desbalanço de potência ativa e reativa como exemplificado na Figura 10. Nesta figura, $P_{G}$ é a potência ativa fornecida pelo gerador, $P_{L}$ é a potência ativa consumida pela carga, $\Delta P_{0}$ é o desbalanço de potência ativa imediatamente antes da ocorrência do ilhamento e $\Delta P_{F}$ é o desbalanço de potência ativa resultante. Note que na Figura 10, no instante em que o ilhamento ocorre, para efeito de ilustração, considerou-se variação instantânea no desbalanço de potência ativa. No caso (a) da Figura 10, antes da ocorrência do ilhamento, a geração de potência ativa é menor do que o consumo das cargas do provável sub-sistema isolado. Logo, existe déficit de potência ativa. Também considerou-se que há déficit de potência reativa nesse sub-sistema para o caso (a). Portanto, após o ilhamento, a tensão e a freqüência sofrem uma queda devido aos déficits de potência ativa e reativa, respectivamente. Com a queda da tensão, os consumos de potência ativa das cargas também diminuem, uma vez que as mesmas são dependentes da tensão. Logo, o desbalanço de potência ativa diminui, conforme apresentado na figura. Em função da redução do desbalanço de potência ativa, usa-se sinal negativo em (25). $\mathrm{Na}$ situação representada pelo caso (b), também há déficit de potência ativa, porém, excesso de potência reativa no provável sub-sistema ilhado. Assim, após a ocorrência do ilhamento, as tensões nodais aumentam, elevando o consumo de potência ativa das cargas. Como conseqüência disso, o desbalanço de potência ativa também aumenta, conferindo um sinal positivo em (25). Quando há excesso de potência ativa e reativa, o desbalanço de potência ativa diminui, conforme ilustra o caso (c). Nessas condições, após a ocorrência do ilhamento, as tensões nodais aumentam levando ao aumento da potência ativa das cargas. Logo, o desbalanço de potência ativa diminui, e emprega-se o sinal negativo em (25). Finalmente, o caso (d) ilustra uma condição de excesso de potência ativa e déficit de potência reativa, antes do ilhamento acontecer. Após este evento, as tensões nodais diminuem devido à carência de potência reativa, levando à redução na potência ativa das cargas. Portanto, o desbalanço de potência ativa aumenta e usa-se sinal positivo em (25).

A análise das curvas de desempenho de relés de frequiência mostra que à medida que o desbalanço de potência ativa diminui, o tempo de detecção aumenta quase exponencialmente. Em razão disso, o fator de correção calculado em (25) não pode ser uniformemente aplicado a diversos valores 
de desbalanço de potência ativa. Admitindo que o fator de correção afeta o desbalanço de potência ativa de forma também exponencial, o desbalanço de potência ativa resultante $\Delta P_{F}$ pode ser obtido por (26):

$$
\Delta P_{F}=\Delta P_{0}^{\frac{1}{P_{f a c}}}
$$

em que $\Delta P_{0}$ é o desbalanço de potência ativa no instante em que ocorre o ilhamento. Este valor deve ser substituído nas equações (4) a (7) para considerar a variação do desbalanço de potência após o ilhamento. Nota-se que o desbalanço de potência ativa não é afetado no caso de cargas tipo potência constante, pois neste caso $N P_{T}=0$ e $P_{f a c}=1$.

\subsection{Relé de Taxa de Variação de Freqüên- cia}

Para o relé de taxa de variação de freqüência, à medida que o desbalanço de potência ativa diminui, o tempo de detecção do relé aumenta segundo uma função logarítmica, diferente do que acontece para o relé de freqüência. Portanto, o fator de correção do desbalanço de potência ativa apresentado na equação (26) não é adequado para desenvolver a fórmula empírica do relé de taxa de variação de frequiência, mas as expressões (24) e (25) são válidas. A obtenção de uma expressão adequada para esta finalidade deve contemplar também o caso mais conservador, o qual está relacionado a cargas do tipo impedância constante e a uma das seguintes situações (Vieira Jr. et alii, 2005):

- Déficit de potência ativa e reativa;

- Excesso de potência ativa e reativa.

Utilizando o sistema teste da Figura 6 e o primeiro dos casos mais conservadores procurou-se estabelecer uma relação entre as curvas de desempenho na presença de cargas potência constante e na presença de cargas impedância constante. Os procedimentos seguintes resumem a obtenção do fator de correção do desbalanço de potência ativa:

- Realizaram-se simulações dinâmicas para obter as curvas de desempenho considerando cargas do tipo impedância constante. As curvas foram obtidas mantendo-se constantes as potências ativas das cargas e variando a potência ativa do gerador desde 0 a 30 MW. Assim, um conjunto de pontos relacionando o tempo de detecção e o desbalanço de potência ativa foi obtido, sendo representado pelos vetores $T_{0}$ e $\Delta P_{0}$, respectivamente, para cada condição de operação simulada;

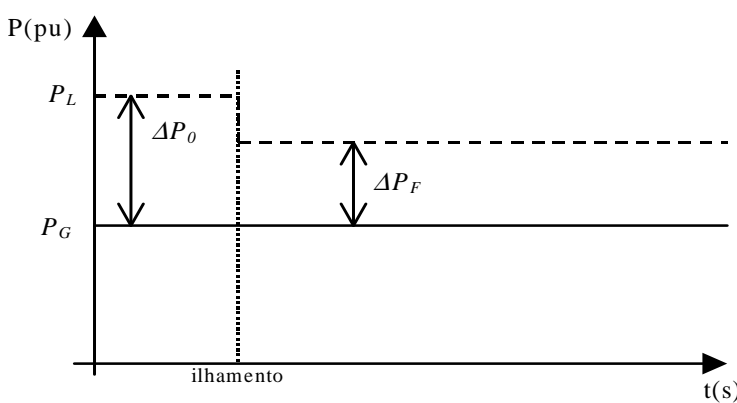

Caso (a): déficit de potência ativa e reativa - redução do desbalanço de potência ativa (sinal negativo).

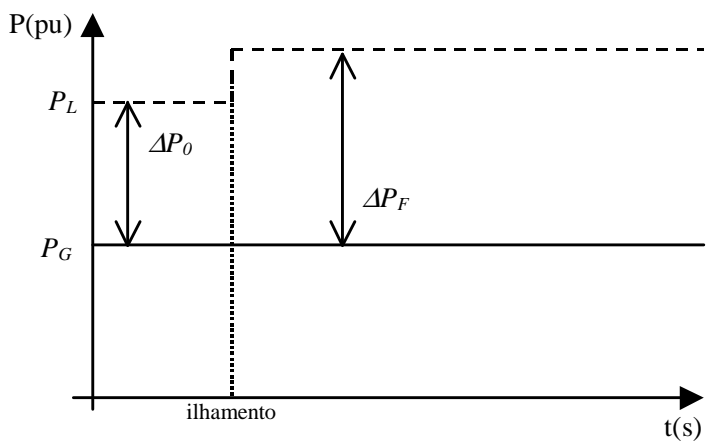

Caso (b): déficit de potência ativa e excesso de potência reativa aumento de desbalanço de potência ativa (sinal positivo) $\mathrm{P}(\mathrm{pu})$

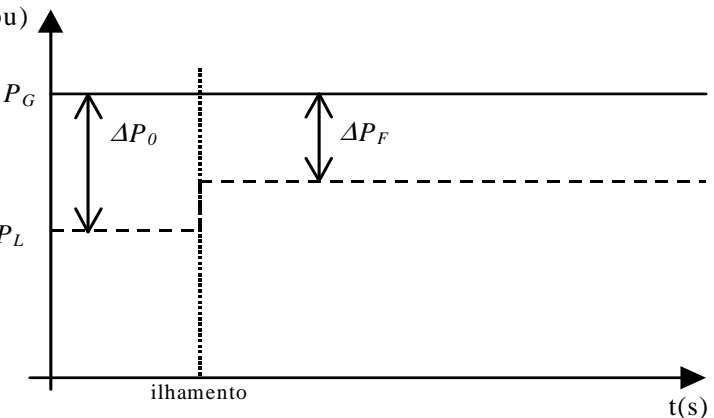

Caso (c): excesso de potência ativa e reativa - redução do desbalanço de potência ativa (sinal negativo).

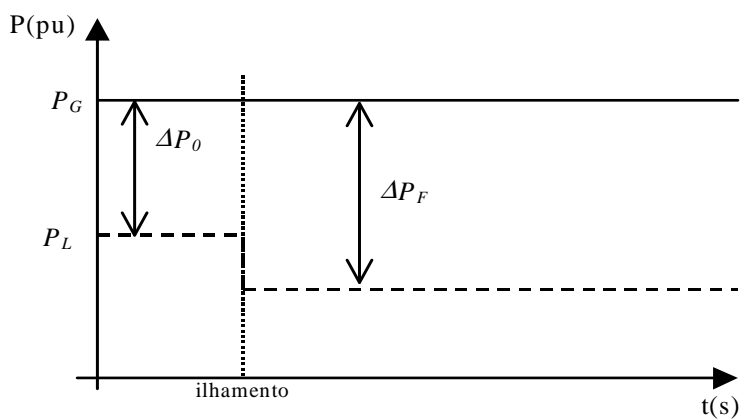

Caso (d): excesso de potência ativa e déficit de potência reativa aumento do desbalanço de potência ativa (sinal positivo).

Figura 10: Determinação do sinal a ser empregado na expressão (25). 
- Os tempos de detecção obtidos no passo anterior foram usados na equação (12) para encontrar os desbalanços de potência ativa correspondentes. Define-se, então, um vetor $\Delta P_{F}$ que armazena os desbalanços de potência ativa calculados pela equação (12). Cada elemento desse vetor pode ser interpretado como o desbalanço de potência ativa necessário para operar o relé no tempo correspondente em $T_{0}$, se as cargas forem do tipo potência constante;

- O próximo passo é estabelecer uma relação entre os valores correspondentes dos vetores $\Delta P_{0}$ e $\Delta P_{F}$. Foi verificado que tal relação matemática é não linear e assim, não existe um fator uniforme a ser aplicado nos elementos de $\Delta P_{0}$ a fim de obter $\Delta P_{F}$. Diversas funções de aproximação foram testadas e a que apresentou resultados mais satisfatórios foi a função logarítmica, em um intervalo de valores entre $200 \mathrm{~ms}$ e $500 \mathrm{~ms}$ para os tempos de detecção. Assim, tem-se:

$$
\frac{\ln \left(\Delta P_{F}\right)}{\ln \left(\Delta P_{0}\right)}=k \Rightarrow \Delta P_{F}=e^{k \cdot \ln \left(\Delta P_{0}\right)}
$$

em que $k$ é uma função.

Quando os passos anteriores foram aplicados a diferentes ajustes do relé de taxa de variação de freqüência, foi observado que $k$ é fortemente dependente do ajuste do relé $\beta$ e de $P_{f a c}$. Então, $k$ pode ser definido como uma função de $\beta$ e de $P_{f a c}$. Por meio de inúmeras simulações dinâmicas com diferentes ajustes do relé, foi observado que a melhor função que define $k$ para o caso mais conservador é:

$$
k=\frac{1}{0,0843 \cdot \ln (\beta)+\left(P_{f a c}\right)^{N P_{T}}}
$$

Portanto, a equação completa para a correção do desbalanço de potência ativa, considerando o caso mais conservador, é apresentada a seguir:

$$
\Delta P_{F}=e^{\frac{\ln \left(\Delta P_{0}\right)}{0,0843 \cdot \ln (\beta)+\left(P_{f a c}\right)^{N P_{T}}}}
$$

O desbalanço de potência ativa corrigido dado pela equação (29) substitui o desbalanço de potência ativa $\Delta P$ nas fórmulas analíticas (11) a (14), resultando nas fórmulas empíricas para avaliar o desempenho de relés de taxa de variação de freqüência.

\subsection{Relé de Deslocamento de Fase}

Em Vieira Jr. et alii (2005) foi demonstrado que o desempenho do relé de deslocamento de fase é muito similar ao do relé de sub/sobrefreqüência para ajustes equivalentes ( em sistemas elétricos de $60 \mathrm{~Hz}$, uma variação de 6 graus elétricos corresponde a uma variação de $1 \mathrm{~Hz}$ ). Logo, o tempo de detecção de relés de deslocamento de fase aumenta quase exponencialmente à medida que o desbalanço de potência ativa diminui. Em razão da similaridade entre os dois relés, o procedimento para a obtenção da fórmula empírica do relé de deslocamento de fase é o mesmo apresentado na seção 4.1 para o relé de sub/sobrefrequiência. Portanto, as equações (22) a (26) são válidas para o relé de deslocamento de fase e o desbalanço de potência ativa corrigido $\left(\Delta P_{F}\right)$, reapresentado na equação (30), deve ser substituído nas equações (18) a (21), resultando nas fórmulas empíricas para avaliar o desempenho desses relés, na presença de cargas dependentes da tensão.

$$
\Delta P_{F}=\Delta P_{0}^{\frac{1}{P_{f a c}}}
$$

\subsection{Validação das Fórmulas Empíricas}

Nesta seção, as curvas de desempenho dos relés baseados em medidas de frequiência obtidas por simulação foram utilizadas para validar as fórmulas empíricas desenvolvidas anteriormente. As simulações foram realizadas considerando o sistema da Figura 6 e cargas do tipo impedância constante. O regulador de tensão do gerador foi configurado para controlar a tensão terminal em 1 pu e duas condições foram simuladas: déficit de potência ativa e excesso de potência ativa. Na primeira delas, há também déficit de potência reativa, levando a um dos casos mais conservadores. Por outro lado, a segunda condição simulada resulta um dos casos mais otimistas, ou seja, de mais fácil detecção, pois há excesso de potência ativa e déficit de potência reativa (Vieira Jr. et alii, 2005). O caso de déficit de potência ativa foi simulado considerando as cargas fixadas em 30 MW e variando a potência do gerador de 0 a 30 MW. Já nas situações de excesso de potência ativa, a potência do gerador foi mantida em $30 \mathrm{MW}$ e a das cargas foi variada de 0 a $30 \mathrm{MW}$.

Para obter as curvas de desempenho dos relés de forma a considerar cargas dependentes da tensão, as seguintes expressões e ajustes foram utilizados:

- Relé de sub/sobrefreqüência: equação (6) devidamente modificada por (26), considerando o ajuste de $\pm 1,5 \mathrm{~Hz}$ instantâneo e $N P_{T}$ igual a 2;

- Relé de taxa de variação de freqüência: equação (13) modificada por (29), considerando o ajuste de 1,0 Hz/s instantâneo e $N P_{T}$ igual a 2;

- Relé de deslocamento de fase: equação (20) modificada por (30), considerando o ajuste de 9 graus e $N P_{T}$ igual a 2. 
Os resultados são apresentados na Figura 11. Os resultados da fórmula analítica também são apresentados, para efeito de comparação. Observa-se uma boa precisão dos resultados da fórmula empírica tanto para déficit quanto para excesso de potência ativa, sobretudo em torno do valor do tempo de detecção requerido igual 500 ms. As maiores diferenças ocorreram para o relé de taxa de variação de frequiência, para valores de tempo de detecção maiores que $500 \mathrm{~ms}$ no caso de déficit de potência ativa. Apesar da existência dessas diferenças, a fórmula empírica produziu resultados conservadores em relação à simulação, ou seja, as curvas de desempenho correspondentes tendem a ser mais elevadas. A Figura 12 compara os resultados da fórmula empírica e da simulação por meio dos desbalanços críticos de potência ativa, considerando 500 ms como tempo de detecção requerido e vários ajustes dos relés baseados em medidas de freqüência. Os resultados apresentados comprovam a precisão da fórmula empírica para o valor de tempo de detecção desejado e também confirmam que, para diferentes ajustes do relé de taxa de variação de freqüência, os resultados são mais conservadores, pois os desbalanços críticos referentes à fórmula empírica são maiores do que os referentes à simulação.

\section{CONCLUSÕES}

As fórmulas desenvolvidas neste trabalho mostraram ser ferramentas eficazes para determinar diretamente o comportamento dinâmico de relés baseados em medidas de frequiência, utilizados na proteção anti-ilhamento de geradores síncronos distribuídos. A boa precisão observada entre os resultados obtidos pelas fórmulas analíticas e aqueles obtidos por simulação dinâmica, utilizando modelos detalhados dos componentes do sistema elétrico, é o principal fator responsável por tal conclusão. Resultados precisos também foram observados quando as fórmulas analíticas foram corrigidas para contemplar casos mais realistas em que as cargas do sistema elétrico são agregadas em modelos dependentes da tensão (potência constante, corrente constante e impedância constante). Essas correções originaram as fórmulas empíricas e foram aplicadas ao desbalanço de potência ativa por meio de fatores obtidos da observação de inúmeros casos simulados em diferentes condições operativas de vários sistemas elétricos.

A fórmula empírica do relé de taxa de variação de freqüência apresentou resultados mais conservadores em relação aos resultados das simulações, o que não inviabiliza seu uso visto que resultados conservadores, na maioria dos casos, podem levar a análises mais seguras para o sistema elétrico.

Finalmente, as fórmulas analíticas e empíricas podem ser empregadas para minimizar o número de simulações dinâmicas necessárias nos estágios de planejamento, implantação e análise de sistemas de proteção anti-ilhamento de gerado-

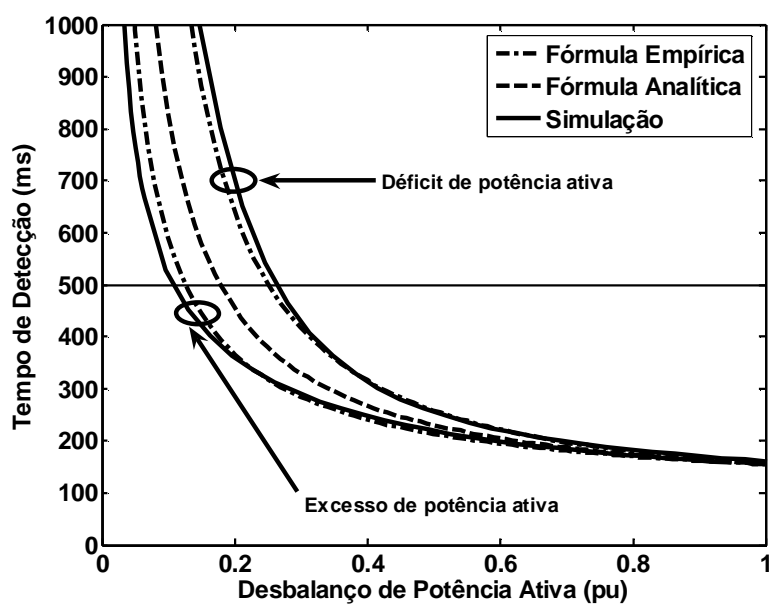

(a) Relé de sub/sobrefreqüência ajustado em \pm 1,5 Hz instantâneo.

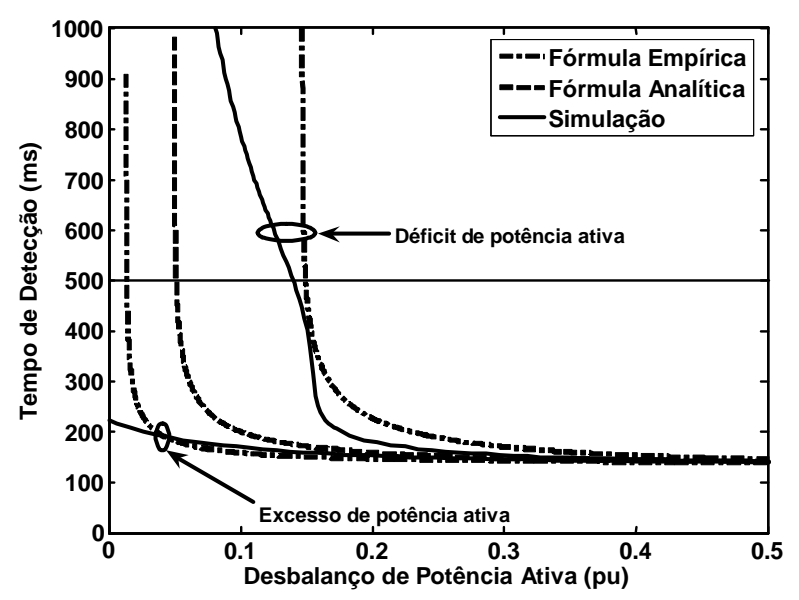

(b) Relé de taxa de variação de freqüência ajustado em $1 \mathrm{~Hz} / \mathrm{s}$ instantâneo.

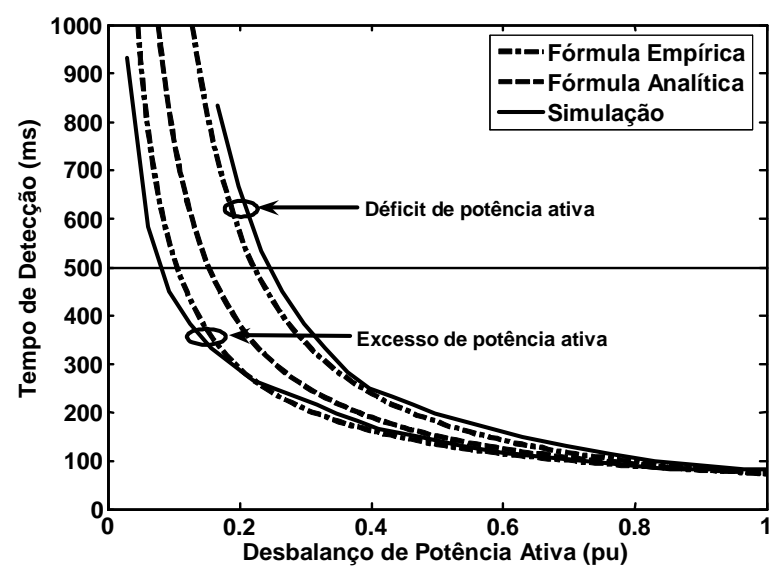

(c) Relé de deslocamento de fase ajustado em 9 graus.

Figura 11: Comparação entre a fórmula empírica, fórmula analítica e simulação. 
res síncronos distribuídos. As fórmulas empíricas, mesmo tendo apresentado uma boa precisão, consideram uma variação média do desbalanço de potência ativa após o ilhamento. Além disso, no caso dos relés de taxa de variação de frequiência, observou-se que a precisão da fórmula empírica é reduzida se o tempo de detecção aumenta, porém os resultados são conservadores. Logo, recomenda-se empregá-las, juntamente com as condições mais conservadoras, quando se desconhece o tipo e/ou o comportamento das cargas do sistema elétrico. Portanto, os resultados obtidos por essas fórmulas, sempre que possível, devem ser refinados por simulação dinâmica.

\section{AGRADECIMENTOS}

Os autores gostariam de agradecer à Fundação de Amparo à Pesquisa do Estado de São Paulo (FAPESP) e ao Conselho Nacional de Desenvolvimento Científico e Tecnológico (CNPq) pelo suporte financeiro.

\section{REFERÊNCIAS}

CIGRÉ Working Group 37.23 (1999). Impact of increasing contribution of dispersed generation on the power system. Technical Report, CIGRÉ.

CIRED Working Group 4 (1999). Dispersed Generation, Technical Report, CIRED.

IEEE Standards Coordinating Committee 21 (2003). IEEE standard for interconnecting distributed resources with electric power systems. IEEE Std 1547-2003.

IEEE Task Force (1993). Load representation for dynamic performance analysis. IEEE Transactions on Power Delivery, vol. 8, no. 1, pp. 472-482.

Jenkins, N., R. Allan, P. Crossley, D. Kischen and G. Strbac (2000). Embedded Generation. London: The Institute of Electrical Engineers.

Kundur, P. (1994). Power System Stability and Control, New York: McGraw-Hill Inc.

Reis Filho, F. A. (2002). Uma Proposta de Algoritmo Digital para Proteção da Interligação Concessionária e Indústria Operando em Sistemas de Co-geração. Tese de Doutoramento, Escola Politécnica da Universidade de São Paulo, São Paulo-SP.

Vieira Jr., J. C. M., W. Freitas e A. L. M. França (2005). Análise comparativa sobre a eficácia de relés baseados em medidas de freqüência para detecção de ilhamento de geradores distribuídos. SBA Controle \& Automação, (abr./jun.), vol.16, no. 2, p.251-261.

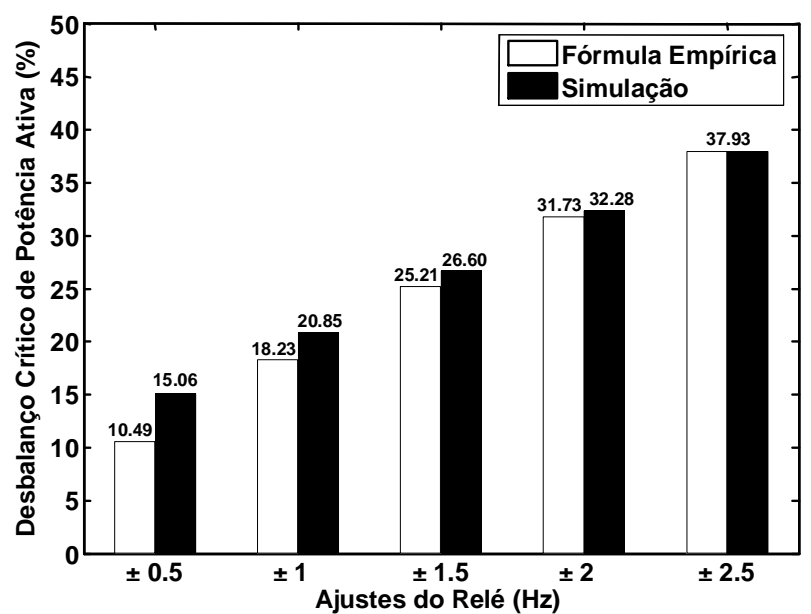

(a) Relé de sub/sobrefreqüência.

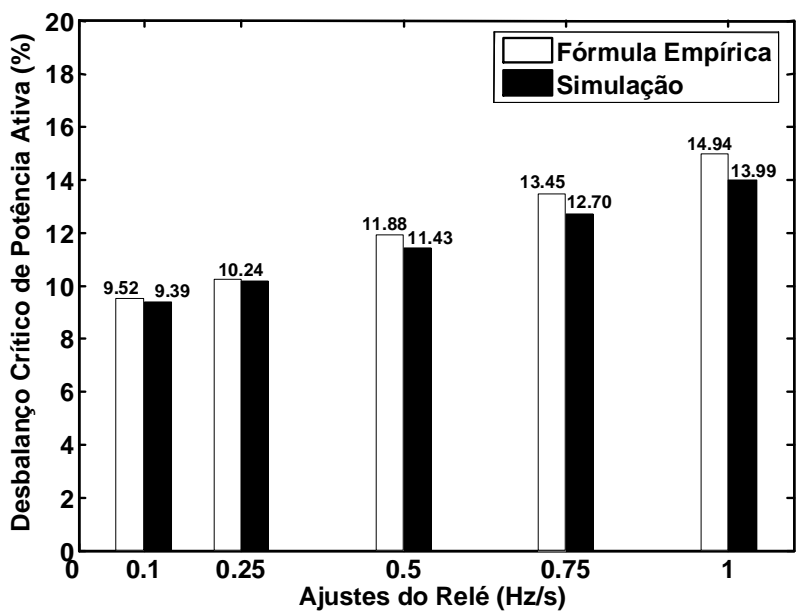

(b) Relé de taxa de variação de freqüiência.

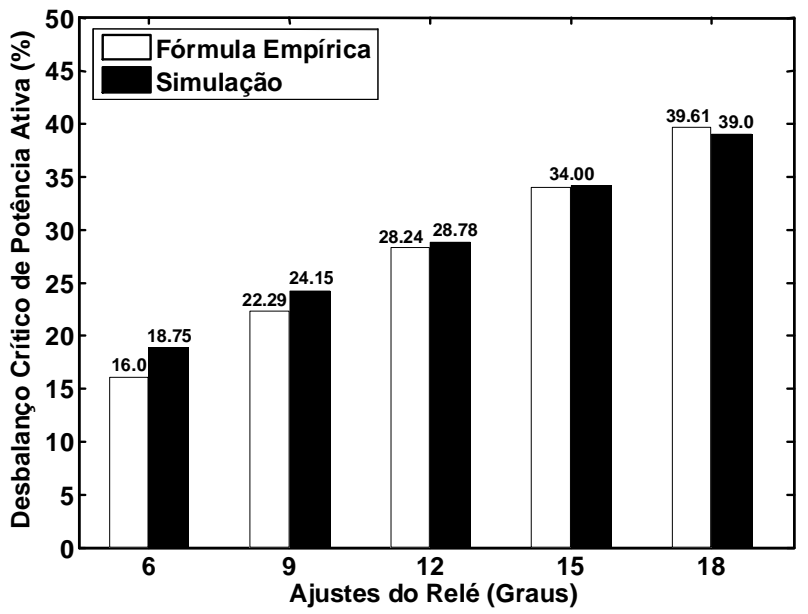

(c) Relé de deslocamento de fase.

Figura 12: Desbalanços críticos de potência ativa: comparação entre fórmula empírica e simulação. 
Vieira, J. C. M., W. Freitas, W. Xu and A. Morelato (2006). Performance of frequency relays for distributed generation protection. IEEE Transactions on Power Delivery, vol. 21, no. 3, p. 1120-1127.

Walling, R. A. and N. W. Miller (2002). Distributed generation islanding - implications on power systems dynamic performance. IEEE/PES Summer Meeting, Chicago, USA, pp. 92-96.

Xu, W., K. Mauch and S. Martel (2004). An assessment of distributed generation islanding detection methods and issues for Canada. CANMET Energy Technology Centre - Varennes, National Resources Canada-Technical Report 2004-074. 